\title{
Archipelago of Risk: Uncertainty, Borders and Migration Detention Systems
}

\section{Angela Mitropoulos}

\begin{abstract}
This essay takes Deleuze's 'Postscript' as a point of departure for a theory of risk analytics. It heeds the advice of the 'Postscript' to dispense with registers of fear and hope and instead focus upon the rough outline of coming forms of power, and the insight it gives to the dynamics of enclosure and flight. The illustrative case in this essay is the Australian 'Detention Network', a vast system of migration detention that has been wholly privatised since 1997 and has served as a laboratory for similar systems in other parts of the world. This illustration tests the limits of normative and constructivist theories of risk. Normative theories explain the ubiquity of risk as a consequence of 'globalisation', the rise of techno-scientific rationality, and the decline of 'traditions' (namely, the gendered division of labour and the family upon which industrial production depended); while the constructivist approach either neglects an explanation of the persistent reconstruction of bounded spaces and time-zones to the dynamics of risk and profit, or tends to place the assemblage outside the changing, conflictual socio-technical history of capitalism.

The principal argument in this essay is that contemporary analytics of risk are preoccupied with integrating uncertainty (or uninsurable risk) into formulations of risk, and that this necessarily gives rise to complex, archipelagic systems of abstract and physical dimensions. Flight transformed the enclosures. That is, this essay reads the Deleuzo-Guattarian concept of the assemblage not as the imperative, philosophical reconstruction of a Platonist 'parts-whole' paradigm, but as an initial step in a critical theory of assemblage. In doing so, it places the emphasis on contracts as mechanisms that assemble stochastic processes into sociotechnical systems and forms of value.
\end{abstract}

Keywords: archipelago, assemblage, borders, capital, contract, Deleuze, detention, finance, Foucault, infrastructure, Knight, migration, risk, statistics, time-zones, uncertainty.

\section{INTRODUCTION}

The pivotal argument in this essay is that contemporary analytics of risk are preoccupied with incorporating uncertainty - a concept which Knight defined as uninsurable risk ${ }^{1}$ - into formulations of risk, and that this necessarily gives rise to complex, archipelagic systems of simultaneously abstract (or mathematical) and physical dimensions. In spatio-temporal terms, the

1. Frank H. Knight, Risk, Uncertainty and Profit, Dover Publications, Mineola, New York 2006. Henceforth Risk, Uncertainty and Profit. 
2. A significant attempt to think the archipelagic is Elaine Stratford et al, 'Envisioning the Archipelago', Island Studies Journal, 6, 2 (2011), 113-30. I would however like to emphasise the temporal dimension as much as call attention to a nonuniform topology.

3. Michel Foucault, Discipline and Punish: The Birth of the Prison, Pantheon Books, New York 1977.

\section{Barbara Adam,} Ulrich Beck and Joost van Loon (eds), The Risk Society and Beyond: Critical Issues For Social Theory, Sage, London 2000.

5. Ulrich Beck, World Risk Society, Polity Press, Cambridge 1999, p2.

6. Ian Buchanan, Deleuzism: A Metacommentary, Edinburgh University Press, Edinburgh 2000, pp120-21; Marieke de Goede, Speculative Security: The Politics of Pursuing Terrorist Monies, University of Minnesota Press, Minneapolis 2012, pp28-29.

7. Julia Chinyere Oparah, Global Lockdown: Race, Gender, and the Prison-Industrial Complex, New York, Routledge 2005; Mitchel P. Roth, Prisons and Prison Systems: A Global Encyclopedia, Greenwood Press, Westport 2006; Eve Goldberg and archipelagic is neither the vast expanse of a continental mass from which parts of the coastline break off to form islands from time to time, nor islands ('isolated-lands') that are yet to sort themselves into continents, but the nonuniform clustering of processes and spatio-temporal variations. ${ }^{2} \mathrm{I}$ begin with this brief definition of the archipelago, and a nod toward Foucault's discussion of the 'carceral archipelago' that, by comparison, will serve as an index of how systems of confinement and risk analytics have changed. ${ }^{3}$ I give an outline of the risk archipelago's function, its historical and technical scope, conditions of possibility and method; go on to illustrate this by way of a contrasting Foucault's 'carceral archipelago' with current migration detention systems (in this instance, the IDN); and in so doing address some key implications for theories of risk (and uncertainty). Chief among the latter are analyses of risk that have on occasion been described as realist versus constructionist theories of risk; ${ }^{4}$ that is, on the one hand theories that explain the prominence and ubiquity of risk (and uncertainty) as a consequence of globalisation (understood as the diminution of the nation-state and its border controls), the rise of techno-science, and the decline of those ostensible traditions (such as the gendered division of labour and the family) on which industrial production depended upon for its reproduction; ${ }^{5}$ and, on the other, theories that, contrariwise, argue that the existence and conglomeration of diverse categories of risk does not imply a determinate ordering amenable to a theory of risk analytics, or that, more broadly, assemblages are not determined. ${ }^{6}$

Migration detention, as with imprisonment in many countries, is increasingly organised through combinations of government, non-government and corporate agencies. In these cases, it often involves billions of dollars in complex economic processes, and is progressively or wholly outsourced to a range of contractors. ${ }^{7}$ Unlike prisons, and particularly in more recent years, migration detention has bundled together the legal exceptionalism of administrative detention with the history of quarantine laws and assumptions, along with a more recent emphasis on national security doctrines of preemption. ${ }^{8}$ This is not to suggest that legal or policy frameworks governing the classification and treatment of refugees, asylum seekers or migration have become irrelevant, although each of these fields has become securitised - in both the military and financial senses of that term. ${ }^{9}$ Here I place particular emphasis on the changing legal-economic form of contracts, which have reshaped the organisational systems of migration detention and are thus deserving of a greater degree of critical attention, especially inasmuch as the integral function of contracts is to price and apportion risk to the contracting parties. ${ }^{10}$ Outsourcing has enhanced the risk-shifting and profit-generating capacities of systems turned, as I argue elsewhere, toward imagined threats and speculative financial gains, of which highly-charged, racialised constructions of undocumented migration and pre-emptive detention serve as powerful conduits. ${ }^{11}$ LiPuma and Lee's criticisms of a naturalist understanding of risk is, I think, a crucial part of this discussion, and their brief linking of the rise 
of the derivative to the spread of outsourcing contracts is a key insight; ${ }^{12}$ but it is overshadowed by a debatable theory of globalisation that overlooks the ways in which, among other things, the delineating function of borders is logically and organisationally prior to 'connectivity' and persists as its condition. A non-naturalist approach to risk also requires a de-naturalisation of the borders that, as I will argue here, are integral to the procedures of risk analysis and its concept of uncertainty.

Methodologically speaking, an analysis of migration detention requires an approach adequate to a field operating in simultaneously legal, economic, financial, medical and governmental registers, precisely because the unrelenting proliferation of contracts has made possible the assembly of generic, archipelagic organisational systems such as those of migration detention. ${ }^{13}$ It is my contention here that contracts are those mechanisms that assemble processes into socio-technical systems. I am disinclined to read the Deleuzo-Guattarian theory of assemblage through the lens of a Platonist focus on parts and wholes rather than - following Canguilhem's understanding of the function of the concept in the history of science ${ }^{14}$ - on the means by which the boundaries between previously discrete domains of practice and fields of knowledge are traversed, recombined and transformed. In this regard, the concepts of risk and uncertainty (or uninsurable risk) did not emerge in sociology but in economics and insurance over the course of centuries - and what one makes of this transmission of key concepts across disciplinary boundaries has significant implications for its theorisation. ${ }^{15}$

Understood outside its disciplinary partitions and resulting practices of risk management, the concept of risk - unlike specific risks understood as dangers or perils - implies the weighing of bounded multiples. It involves ratios, ratios of ratios. Since the eighteenth century, the concept of risk has assumed delineated zones of event distribution drawn into relative proximity by mathematical formulation operating in an uncertain, volatile ocean. In its conventional formulations, uncertainty was extraneous to the cognitive-material delineation of more or less stable populations and associated statistical measures and inferences regarding the reproduction of their properties. Where it appeared within this framework, it did so in the manner of deviations from statistical averages. Conventional (or disciplinary) approaches to risk management - as in the legal concept of liability or the social welfare concept of 'at-risk' - utilise a singular (or realist) definition of risk (as discrete risks rather than a ratio) because the techniques of discipline (rather than those of control) assume a transcendental, exterior dimension of risk analytics. This can be construed as a political realm or moral-ethical domain outside/above that of economics. Yet such precepts are inapplicable to contexts in which continuity of classification and predication is precisely that which is in doubt (as in the case of 'irregular migration'), and where, more broadly, it is less an instance of management than the monitoring and inculcation of self-management (as with control). Moreover, the contemporary archipelagic
Linda Evans, The Prison-Industrial Complex Eं the Global Economy, PM Press, Oakland 2009; Roxanne Lynne Doty and Elizabeth Shannon Wheatley, 'Private Detention and the Immigration Industrial Complex', International Political Sociology 7, 4 (2013), 426-43; Michael Flynn, 'There and Back Again: On the Diffusion of Immigration Detention', Journal on Migration and Human Security 2, 3 (2014), 165-97; Daniel Wilsher, Immigration Detention: Law, History, Politics, Cambridge University Press, Cambridge 2012.

8. Thomas C. McMullen, The Bush Doctrine: Power Concepts, Preemption, and the Global War on Terrorism, US Army War College, Carlisle Barracks, Pa. 2004; Don McMaster, 'Detention, Deterrence, Discrimination: Australian Refugee Policy' (PhD, University of Adelaide 1999).

9. Scott D. Watson, The Securitization of Humanitarian Migration: Digging Moats and Sinking Boats, Routledge, London 2013; Alison Gerard, The Securitization of Migration and Refugee Women, Routledge, London 2014.

10. Pat O'Malley, Risk, Uncertainty and Government, GlassHouse, London 2004; Angela Mitropoulos, Contract 
and Contagion: From Biopolitics to Oikonomia, Minor Compositions/ Autonomedia, New York 2012.

11. Angela

Mitropoulos,

'The Performative Economy of the

Racial Speculative', in States of Race, Australian Critical Race and Whiteness Studies Association Conference,

Brisbane 2014.

\section{Financial} Derivatives and the Globalization of Risk, Duke University Press, Durham NC 2004, p20.

13. Mitropoulos, Contract and Contagion.

14. Pierre-Olivier Méthot, 'On the Genealogy of Concepts and Experimental Practices: Rethinking Georges Canguilhem's Historical Epistemology', Studies in History and Philosophy of Science 44, 1 (2013), 112-23. http://doi.org/7d2

15. Notably, Beck's theory of 'risk society' addressed risks but not risk, and, more curiously, presented a (transcendental) concept of uninsurable risk (without using that term) without directly engaging with Knight's discussion of its role in relation to profit - yet, nevertheless, sought to explain that concept through the classical sociological arrangement of risk analytics is as much a diagram of the bundling of different categories of risk in the strategy of risk management known as portfolio diversification; or the assembling of sets in the Cartesian coordinates of a risk profile; or those islands generated in the imagination of possible worlds by way of 'reviewing several imaginative scenarios ... about what is likely to happen and how key variables can change'; ${ }^{16}$ as it is a description of the physical organisation of zones through which risk is captured, shifted, unleashed or exteriorised, and through which people and things move.

As for the illustrative case in this essay: in Australia, migration detention has been entirely outsourced to various companies since 1997, beginning with Australasian Correctionals Management (a subsidiary of the US prison company, Wackenhut). At present, the two largest corporations holding contracts are Serco ('Bringing Services to Life') and Transfield Services, with the contracts for the latter to manage detention centres on Nauru and Manus Island exceeding $\$ 3$ billion (AUD), equivalent to some $€ 2.2$ billion, in the last two years. ${ }^{17}$ Both Serco and Transfield are publicly-listed companies trading on London and Australian stock exchanges, and their largest investors are pension funds and investment management companies.

\section{UNCERTAINTY IN THE CIRCUITS OF VALUE}

The coils of the serpent are even more complex than the burrows of the molehill

\section{Gilles Deleuze, 'Postscript on the Societies of Control'}

It is imperative that we bear in mind that the serpent's tail is always in the serpent's mouth ...

\section{Frank Knight, Risk, Uncertainty and Profit}

I treat migration detention as a part of a circuit of value, in the sense that Marx pondered the algebraic formula of industrial capital as M-C-M. ${ }^{18}$ It is a circuit of valorisation involving both manifold coils (Deleuze's serpent), as well as the mythical symbolism of tautological circularity (Knight's serpent), wherein economic processes are expressed as the seemingly magical transformation of money (M) into money again, of higher value (M'); and in contrast to the industrial systems and the value-form that Marx analysed in his day, these are circuits in which uncertainty fulfils the transformative function within key processes. For classical political economists such as Ricardo, and in the early writings of Adam Smith, the metamorphosis was explained by recourse to the labour theory of value; ${ }^{19}$ but here it pertains to and is modified by a speculative economy that - as Deleuze hints at in the 'Postscript on the Societies of Control' - is concerned not with the seemingly linear production of things but, instead, with the indefinite delivery of services and the buying and selling of joint stock. ${ }^{20}$ The circuits of speculative value involving 'services' 
manoeuvre around the threshold of unclassifiable, unknowable, incalculable but nevertheless estimable risk (i.e. uncertainty), throwing up putative problems that, conventionally, were tangential to the metrics and methods of industrial production, relegated to either side of its formulations as parts of the 'secondary circuit of capital', as questions about the homely reproduction of the wage-labourer, or the circulation of value through urban landscapes, and associated dilemmas of demand management and the realisation of value. ${ }^{21}$ These circuits of capital and its notational systems are, of course, the trace and effects of power, inscriptions of contractual arrangements that are no more eternal than the movements that contest and transform them. They are the hieroglyphics of socio-technical systems, and may be as explanatory and illuminating as they can be mystifying of key, contested processes.

Whereas Marx's discussion of political economy's understanding of the circuits of industrial capital emphasised the energy and capacity generated within the 'hidden abode' of labour, or the crises of realisation that occurred in circulation, contemporary risk analysts derive an estimate of value from speculations on uncertainty through correlations of intensities of divergent qualities and their conversion into the extensive, divisible language of geometry - or, briefly put: the use of technical procedures for assigning values to affective intensity and calculable risk, respectively. ${ }^{22}$ Uncertainty, in this sense, is the intensive, or affective, dimension of risk analytics. It is a concept that remains, as DeLanda says of the rise of the intensive sciences, within the field of thermodynamics. Uncertainty involves ranges of intensity that cannot be measured by those instruments attuned to calculable risk. Heat is not a yard of linen; uncertainty is not a roll of the dice. It is possible to situate uncertainty within a post-Fordist historical frame, but it is not insignificant that the very concept of risk, which emerged in Early Modern Europe as the financial instrument for calculating maritime insurance premiums by weighing possible losses against possible gains, was paralleled by Spinoza's definition of affect in similarly intransitive and proportional terms, that is: 'anything that increases or diminishes' the body's capacity to act and the mind's capacity to think. ${ }^{23}$ Affect, by this definition, refers to combined stocks, or 'joint-stock', as in the pooling of risk through joint-stock companies that trade on stock exchanges. Uncertainty in this abstract sense is not a feeling so much as a concept around which techniques for ascertaining the value of feelings about an unknowable future emerged across the fields of insurance, economics and philosophy. The very possibility of pricing risk in economic processes geared not toward the production and circulation of things (as in manufacturing), but, instead, increasingly organised around personalised interactions (however automated or intimate they might be) and speculation (share-price, market confidence), requires quite different formulations of risk and taxonomic premises to those that relied upon the elaboration of statistical probabilities.

In Knight's presentation of the circuit of capital, the two conditions of
(Ferdinand Tönnies') paradigm of the distinction between Gemeinschaft and Gesellschaft. See Beck, Risk Society.

16. Clive Vaughan Jones, 'Financial Risk Analysis of Infrastructure Debt, the Case of Water and Power Investments', 1991.

\section{Evershed,} 'Mandatory Immigration Detention Is a Billion-Dollar Business - Analysis'.

18. Karl Marx, Capital: A Critique of Political Economy, Volume II, Book II, Progress Press, Moscow 1978, pp25-64.

19. Diane Elson, Value: The Representation of Labour in Capitalism, Humanities Press, London 1979.

20. Gilles Deleuze, 'Postscript on the Societies of Control', October 59 1992, pp3-7. Henceforth 'Postscript'.

21. The Urbanization of Capital, Blackwell, Oxford 1985

22. This is a quite different reading of Deleuze and Guattari's writings on affect from those offered by Massumi and De Landa, but it is nevertheless indebted to both. Brian Massumi, Parables for the Virtual: Movement, Affect, Sensation, Duke University Press, Durham 2002; Manuel De Landa, 
Intensive Science and Virtual Philosophy, Continuum, London 2010.

23. When Spinoza was born in Amsterdam, to a family that owned an importing business in the early seventeenth century, that city had just become the major centre of European trade, shipping and, in particular, marine insurance. I discuss this at greater length in the essay 'Spinoza's Affection' (forthcoming). See also, Benedictus de Spinoza, Ethics, Oxford University Press, Oxford 2009; Sabine Go, Marine Insurance in the Netherlands 16001870: A Comparative Institutional Approach, Aksant, Amsterdam 2009; Ranald C. Michie, The Global Securities Market: A History, Oxford University Press, Oxford 2008.

24. Though perhaps without recourse to their sometimesexplicit primitivism. A Thousand Plateaus: Capitalism and Schizophrenia, University of Minnesota Press, Minneapolis 1987 , p204.

25. This is the thesis of the "autonomy of migration' from the boundaries and scope of the political. See Mitropoulos, 'Autonomy, Migration, Recognition', in Constituent Imagination: Militant Investigations, Collective Theorization, above-average profits (and losses) are uncertainty and borders - though most readings of Knight skip over the second of these in a move that serves to naturalise their presence in registers of uncertainty. Still, as Knight puts it: if all risks could be calculated and known in advance and there were no barriers to entry into competition, profits and losses would converge to zero. Thus, Knight argued, it was not risk ('a quantity susceptible of measurement') that generated profit but, instead, 'unmeasurable uncertainty' (Risk, Uncertainty and Profit). Where the calculation of risk is concerned with a priori and statistical knowledge derived 'from an inductive study of a large group of cases', formulations of uncertainty are based on estimates. Crucially for Knight, uncertainty arises where 'there is no possibility of forming in any way groups of instances of sufficient homogeneity to make possible a quantitative determination of true probability', and yet it remains possible to accord an estimate with a value because it 'has the same form as a probability judgement; it is a ratio, expressed as a proper fraction' (p231). In Knight's overall schema, the threshold between uninsurable risk and borders is where the possibility of above-average rates of profit and losses emerges, and it is notable that he construed uncertainty as a mechanism of selection (reminiscent of Darwin's theory of natural selection in its non-transcendental structure, albeit with a reversal of its temporal schema). Knight's derivation of profits and losses from the incalculable but estimable unknown underlines the ways in which the contemporary analytics of risk is turned to that which is in excess of both the empirical present and a strictly calculable future. It also illustrates the sense in which delineation and classification are as integral to the practices of valuing risk as are the drawing of connections between diverse distributions and imagined future values.

In any case, my argument here is that the pricing of risk (inasmuch as it depends on formulations of statistical probabilities) is premised on continuous classification into the future; whereas uncertainty by contrast grasps the technical inapplicability of probabilistic science to stochastic processes and, more saliently, to a world in which continuous, predicated classification has been challenged by movements against the enclosures. Therefore, while it is possible to trace the history of technical and scientific shifts in which there is an increasing emphasis on the random variable (some of which I do below), it is also crucial to bear in mind that technical advances are granted widening fields of applicability in light of social conflicts that transform the classificatory schema relied upon by prior systems - specifically in this case, the extent to which conventional calculations of probabilistic risk are premised on the persistence of predicated, bounded classes in the future. While neither Deleuze's 'Postscript' nor Foucault draw these implications from their respective discussions of the enclosures and the 'carceral archipelago', it can nevertheless be elaborated from the emphasis Deleuze and Guattari elsewhere place on 'lines of flight'; ${ }^{24}$ and as an explanation for the indefinite processes of socio-technical change in this instance. ${ }^{25}$ 
Deleuze's 'Postscript' appeared in the early 1990s, at the same time as the illustrative case referred to here - the IDN - was under construction. That brief essay spoke as much to questions of the historical transformation of the socio-technical systems of capitalism as it spoke bluntly of a frustration with obsolete analyses of power. The 'Postscript' begins with the suggestion that it is the 'crisis' of 'the enclosures' - those of the unions, the family, the schools and factory - which precipitates the shift to the 'societies of control', and it concludes with the remark that it is 'up to [a younger generation] to discover what they're being made to serve, just as their elders discovered, not without difficulty, the telos of the disciplines'. The 'Postscript's' importance, given this, lies not in what can be canonised. It is, on the contrary, a materialist insistence on the importance of a 'socio-technological study of the mechanisms of control' to the possibilities of 'new forms of resistance' ('Postscript', p7). Deleuze does not ask whether there is resistance or it is of a sufficient magnitude. There is always, everywhere resistance. Instead he poses a question about how radical theory understands its object. Deleuze was not alone in arguing for a shift in understandings of what capitalism is and was becoming. What is specific to the 'Postscript' is that it approaches this question in the absence of nostalgia and without boosterism: 'There is no need to fear or hope, only to look for new weapons. ${ }^{26}$ Furthermore, it urges us to 'grasp the rough outlines of ... coming forms' of power (p7). Here, I want to make similar points with regard to Australia's regime of border control that has not only expanded in reach, complexity and the calibration of its systems of control, but, for more than two decades, has served as a capacious, well-funded laboratory for techniques that have been exported around the world. ${ }^{27}$

\section{NETWORKING ENCLOSURES AND CAPTURING UNCERTAINTY}

Statistics: mixture of G4S and transferees. Twenty-two minor injuries. Thirteen serious. One critical. One person is dead ... Air ambulance is on the way.

Australian Department of Immigration and Border Protection briefing to staff, Manus Island Regional Processing Facility, Papua New Guinea, 17.2.14.

... a system of variable geometry the language of which is numerical ... a sieve whose mesh will transmute from point to point.

Gilles Deleuze, 'Postscript on Societies of Control'

The Australian Government refers to the combined agencies and facilities of migration detention as the 'Immigration Detention Network' (hereafter IDN). Its three largest facilities are 'off-shored' on the legally-excised Christmas
Stevphen Shukaitis, David Graeber and Erika Biddle (eds), AK Press, Oakland 2007.

26. Ibid, p4.

27. Most recently, the European Commission announced the expansion of offshore processing of asylum seekers: www.theguardian. com/world/2015/ mar/05/europeancommission-thirdcountry-immigrantprocessing-centres. 
Island (situated more than 3000 kilometres, or more than 2000 miles, from the mainland), on the Pacific island micro-state of Nauru, and on Manus Island in Papua New Guinea. Leaving aside hundreds of individualised (often short-term) staff contracts, the IDN includes just under 2000 subcontracting arrangements with 500 different organisations. Detention is often referred to as 'administrative detention' because it involves the confinement of people who have not been charged with a crime. It is not subject to the formal, reviewable terms of judicial confinement, or, in particular, its temporal coordinates. It evades the correspondences between the performance of an (illegal) act in the past and the confinement that takes place in an often-indefinite present, absolved by vague - but unmistakeably racialised forebodings of the likely future consequences of the absence of detention, thus overturning the presumption of innocence and trial that otherwise shape the procedural time-lines of criminal and civil law.

I identify five ways in which the IDN involves the incorporation of uncertainty into the analytics and systems of risk:

through the application of principles of variable geometry in the engineering of flexible and adaptive physical constructions and legal entities (contracts) that seek to optimise uncertain rates of flow;

by converting the uninsurable risk of undocumented, sea-crossing migration into the calculated risk of profits gleaned from outsourcing and 'public-private partnerships' (or PPPs);

through the use of contingency accounting methods and the spread of contingency business management theory;

through the exploration of 'hybridised' methods of risk analysis which blend scientific and aesthetic forms of conjecture;

through time-bound correlations between diverse categories (or classifications) of risk, such as contingent convertible notes (which derive their value from speculation on the divergence of ratio within a set period of time) and insurance-linked securities (or ILSs, which involve 'hybrid' forms of financing).

These five aspects can be summarised as pertaining to, respectively: (1) organisational structures; (2) exchange processes; (3) accounting control systems; (4) analytical methods; and (5) financial instruments. They are not elements which can be empirically disassembled, since they do not refer to Platonic solids that may or may not form parts of a whole, but, on the contrary, to particular functions and processes that comprise a dynamic system. What is specific to this system can be ascertained by comparing it to Foucault's 
discussion of that which obtained in Mettray.

In Discipline and Punish: The Birth of the Prison, Foucault wrote of Mettray that "[i]t was the most famous of a whole series of institutions which, well beyond the frontiers of criminal law, constituted what one might call the carceral archipelago'. Mettray - or the Colonie Agricole Pénitentiaire de Mettray opened in 1840. It was a private reformatory for delinquent boys. As Foucault describes it, its staff were 'technicians of behaviour: engineers of conduct, orthopaedists of individuality'. Their task was 'to produce bodies that were both docile and capable'. Describing a system where inmates are moved through daily routines that resembled the hierarchical forms of the family, army, factory and school, Foucault presents Mettray as 'the disciplinary form at its most extreme, the model in which are concentrated all the coercive technologies of behaviour', and one that, unlike the arbitrary confinements of 'the classical age', constituted a 'subtle, graduated carceral net' focused on normalisation. ${ }^{28}$ Its most prominent features were its distance from 'frontiers of criminal law' and its preoccupation with the identification and normalisation of deviancy. These were the procedures of the behavioural focus of the reformatory directed toward the manufacture of docility and capacity. As we shall see, contemporary analytics of risk, while retaining the concept of 'capacity' (a concept whose thermodynamic significance I noted above), nevertheless places far greater emphasis on the pre-emptive identification of (non-linear, random) non-compliance and, simply put, 'desire'.

The reasons for this can be explained by understanding the precise and inherent limits of statistical reasoning to (what policy documents often refer to as) 'irregular migration'. Statistical norms are derived from the distributional cluster of frequencies around a mean or average, and often graphically presented as a bell-shaped curve. Foucault, of course, underlined the etymology of statistics as a 'science of the state'. ${ }^{29}$ Statistical norms rely upon classifications of events, people, or aggregations of things (as sets), extrapolate understandings of the characteristics of those sets from the upper arc of the mean, and enable the discernment of ratio as an instrument of comparability in a quantified continuum - hence Foucault's use of the phrase 'graduated carceral net'. There are no statistics without the delineations of populations or sets. Yet the possibility of generating 'social facts' (in the Durkheimian sense) about the properties of such delineations and their relative proportions, while abstractly infinite, is in practice constrained by assumptions of classificatory self-evidence and/or the transitive character of nominalism, hence the historical alignment of statistical reasoning with racial classifications in, most notably, the work of Cuvier and Galton. ${ }^{30}$ The tendency to naturalise the boundaries of circumscribed populations and their attributed characteristics (as data) is also apparent in the related but positive affirmations of the average. The average Australian is descended from English ancestors as a consequence of a range of policies over more than two centuries, including that of the 'White Australia' policy in migration, which
28. Discipline and Punish, pp294-99.

29. The Foucault Effect: Studies in Governmentality, University of Chicago Press, Chicago 1991, pp99.

30. Tukufu Zuberi, Thicker than Blood: How Racial Statistics Lie, University of Minnesota Press, Minneapolis 2001. 
31. Desrosières,

The Politics Of Large Numbers: A History Of Statistical Reasoning, Harvard University Press, Cambridge 1998, p67.

32. Adolphe Quetelet, $A$ Treatise on Man and the Development of $\mathrm{His}$ Faculties, W. and R. Chambers, Edinburgh 1842.

33. A.N. Kolmogorov, Foundations of the Theory of Probability, Chelsea, New York 1956; A. Livi and Roberto Vulpiani, The Kolmogorov Legacy in Physics: A Century of Turbulence and Complexity, Springer, New York 2003; William Edwards Bayes, $A n$ Essay towards Solving a Problem in the Doctrine of Chances, Hafner, London 1963.

34. J.M. Smith and Adrian Bernardo, Bayesian Theory, Wiley, New York 1994, p4. was not officially ended until the mid-1980s, and this average is invoked as both essence and value. The conceptual and technical slippage that the statistical norm affords between the statistically-constructed norm itself and the routine ascription of essential properties to a class of persons (or events, things, nations, etc) gives rise to the techniques of normalisation. Statistical reasoning materialises the typologies of ideational categories by making single units out of multiples, decomposing those units into new manifolds that, in turn, become the object of action. ${ }^{31}$ In the $1830 \mathrm{~s}-40 \mathrm{~s}$, at around the same time as the establishment of Mettray, Quetelet linked statistics with the speculative techniques of the probabilistic sciences. ${ }^{32}$ For him as for others, probabilities involved variability but - having taken his cue from Rousseau's social contract as the basis of social regularities and their ordered continuity into the future - this was posed as a question about future deviations from the average; in this case, what he termed 'the average man' and, by implication, the social deviant.

The problem, however, is that while statistical probabilities can be used to indicate what might happen in the future based on information gathered about the frequencies of past occurrences, this technique is of limited use in the analytics of risk precisely for the same reason that Quetelet regarded it as an important technique of social policy: the so-called 'law of large numbers' is inoperative at the level of one, the relation between each one to another, and so on. Statistics continue to be an important part of the analytics of risk, but in the context of the migration detention network they are far more amenable to the a posteriori (after the event) development of techniques of managing detainees, estimating potential liabilities, and assigning a value to a given frequency distribution of events. Yet, inasmuch as statistical knowledge renders the future as an epistemological or computational challenge, and thus mechanically tends toward the amassing of ever-greater amounts of data, it cannot however tell us what will happen in the future because it is inapplicable to stochasticity of each one. The use of statistical norms in the Quetelian sense is a function (and prescriptive future-projection) of continuous classification and delineation. This is why, briefly put, the probabilistic sciences (from Kolmogorov in the 1930s on) will search for ways of integrating uncertainty by way of the formulation of axioms turned toward conditional probabilities with regard to the random variable; and henceforth (from the 1940s on) to mathematical equations of turbulent rather than laminar flows (Kolmogorov) and the non-standard or nonfrequentist complexities of Bayesian probability. ${ }^{33}$ Bayes's 'doctrine of chances' nevertheless remains parametric: it relies on the delineated construction of priors in finite samples. It has been significant in the development of rational choice theories preoccupied with utility-maximising behaviour whose goal, 'in effect, is to establish rules and procedures for individuals concerned with disciplined uncertainty accounting'; ${ }^{34}$ but it remains bounded by the constraints of priors and finitude. Similarly, Kolmogorov's understanding of 
turbulence is scale-invariant. Applied to higher orders of complexity, statistical self-similarity breaks down because there is no functional constant in the equation. And so, as I argue elsewhere with regard to the fractal modelling of finance, viruses and the mathematical function of 're-normalisation', despite these attempts to mime the stochastic, such methods nevertheless reinstate boundaries into the future and in some fashion, albeit as parameters, patterns and the (Platonist) rule of isometry. ${ }^{35}$

The formulations of variable geometry, by contrast, seek to optimise the performance of a machine in relation to inconstant flows. Detention centres on Manus and Nauru are, in terms of physical design, the corollary of mining encampments or just-in-time architecture, comprising shipping containers as accommodation units, demountables, temporary fencing, and so forth. A similar feat of episodic, adaptive construction is accomplished in the engineering of financial instruments and contracts, and in the assembling of diverse categories or classes of risk. In engineering, variable geometry is associated with the design of dynamic physical structures (such as jet turbines) that respond to changing conditions by modifying the aspect ratio between components in such a way as to optimise the capacity of different flow rates. It is not so much form following function as form responding to flow. In international relations, the term variable geometry has been used to refer to the differential integration of states or zones in contractual agreements at different speeds ${ }^{36}$ Castells utilised the term to depict the architectural reorganisation of the post-cold war global division of labour. ${ }^{37}$ For his part, he envisaged this as a digression from a standard continental form. But leaving aside the geophilosophical premises of a continental imaginary, it should be noted that the temporal dimensions of the archipelagic are as crucial as its spatial co-ordinates. Because there is no natural, uniform measure of time, instruments of abstraction (such as those of analytic geometry) are decisive to the processes that make it possible to construct both the necessarily sequential time of exchange (as with bitcoin's blockchain) and the temporal divergences that are indispensable to even the most infinitesimal practices of arbitrage and hedging within financial markets. The theory of time-space compression does not accord due consideration to such processes. That said, just as the engineering applications of variable geometry illustrate how engines can transform in response to changing conditions by altering the proportions or aspect ratio between components, the archipelagic is similarly disposed to the variability of its components so as to be responsive to changing rates of flow, because the question is not only how to manage currents, but also the optimisation of performance in relation to those flows, so as to generate a speculative value in excess of expenditures and the relative performance of share-markets. Analytic geometry (and calculus) is the shared language of engineers, statisticians, insurers, demographers and so on. It discerns the variable relationship between two or more things (such as lengths, volumes, curvature, inertia) formulated in a notational system which alphabetises
35. Contract and Contagion, p154.

36. 'Variable Geometries: Mapping Ideas, Institutions and Power in the Wider Europe', CEPS Working Document, 254, 30 November 2006.

37. The Rise of the Network Society, Blackwell, Oxford 1997, pp146-47. 
38. 'Annihilating the Logic of Risk: Israel's Military Occupation and the Ascendancy of Hamas', in The Aesthetics of Risk: SoCCAS Symposium Vol. III, John C. Welchman (ed), JRP/ Ringier, New York 2007, pp81-112. a range between known data and objects whose properties are known to unknowable, from alpha to omega. Within the IDN, or indeed similar systems, risks can be transferred, offset and hedged because the formulations that price and allocate risk within contracts furnish time-bound sources of revenue and islands of event distribution, generating a ratio that can be correlated with other ratio - which is to say, bundled or securitised, and subsequently heaped into investment portfolio. The IDN involves significant downside risks for contractors and (somewhat less for) investors, but it also promises high rates of return that exceed any cost-benefit analysis, while at the same time furnishing a discrete time-frame during which the tender is in operation. While a variety of methods for calculating risks are put to use in the IDN, the economic value of detention is derived from the connections and delineations within and beyond those processes, made possible by the variable geometry of facility design (the re-engineering of scalable, adaptive infrastructures borrowed from military, shipping, construction and mining operations) and the similarly variable contingency provisions of contractual arrangements, accounting procedures and securities.

What is remarkable, however, is that the delineations of time within and through financial instruments (as with the setting of expiry dates in options, or the transactional dates set by futures, forwards and swaps) are paralleled by the similarly futurial but (conversely) undefined or indefinite time of preemption, detention and deterrence. It is the nexus created between these two temporal registers within the IDN (i.e. the introjection of incalculable risk, or the generation of uncertainty alongside the processes and classifications of calculable risk) that gives rise to the speculative possibility of above-average profits and losses. Gordon and Filc's discussion of the creation of uncertainty in the West Bank and Gaza offers an important clue to the ways in which abolishing/converting risk of one class relates to generating uncertainties of other kinds. As they put it, the intentional production of local processes whose aim is to destroy the ability of certain segments of society to manage risks' generates the kind of uncertainty that results in protests assuming the form of self-destruction, as with suicide bombings. ${ }^{38}$ The IDN is similarly characterised by the destruction of the ability of those who are detained to decide what risks to take with their lives, with the result being that suicide and self-harm are extraordinarily high, and rise in direct proportion to increases in the uncertainty created by indefinite detention; their frequency is routinely recorded as statistical information used in risk management strategies concerned not with past actions but instead oriented by the combined precepts of utility-maximisation and pre-emptive speculation. A report by Serco entitled 'Enhancements to the Immigration Detention Operating Model' stated the issues as follows:

From intelligence collection and analysis it is clear that a growing level of uncertainty exists amongst the detainee population. This has in turn 
manifested into an unpredictable risk profile that involves adverse behaviour to gain attention and ultimately raise detainee profile. ${ }^{39}$

Suicides and self-harm in detention have regularly been presented by IDN agencies as means of gaining attention, reflective of the fact that detainees have been denied the legal status of adults - by those same agencies. The report's understanding of the subsequent risks that arise as a consequence of abolishing the contractual agency of those in detention makes for interesting reading, as do the recommendations for managing and pre-empting the risks that arise as a result:

the immediate risk proposition [which it records as increased 'noncompliance' and a six-fold increase in the rate of suicides] and a series of longer term trends have also begun to emerge that if not properly identified and used to adapt the operating model will cause consequences such as the inability in achieving objectives, significant cost overruns and considerable reputational harm.

The report lists a typology of 'inappropriate behaviour likely to increase' due to increasing time spent in detention and deportations, including selfharm, 'increased tension and acts of aggression/violence directed at staff', 'non-compliance or participation in large scale protracted protest activity', destruction 'to property and infrastructure', and attempts 'to escape or abscond from detention' (pp2-4). Formulated in meetings between Serco and the Department of Immigration and Border Protection (DIBP), it recommends a combination of punishments and rewards, such as the automatic use of isolation rooms or online shopping vouchers. On the one hand, it outlines a proposed risk management strategy in the familiar terms of rational choice theory and behavioural modification through crude 'rewardpunishment' mechanisms (pp5-6). On the other hand, it recommends a shift from a posteriori risk assessment techniques to those of pre-emption based on estimates of the 'ability' and 'desire' of individual detainees:

current detainee security risk assessment tools have been shown to be an unsuccessful predictor of future behaviour. At present, the IDN uses a risk methodology that applies an automatic and arbitrary low assessment to detainees. This low assessment is only escalated when the detainee exhibits behaviour and actions ... which would justify an escalation of the assessed rating.

While effective when managing the standard linear approach of escalating behaviour, it is Serco's view that it is not effective against a more sophisticated threat environment that is likely to manifest from a detainee cohort experiencing extended periods of detention and where
39. Serco,

'Enhancements to the Immigration

Detention Operating Model', 21.2.14, p2. 
there is greater uncertainty as to their pathway. It is Serco's experience that in this environment benign behaviour can escalate to more serious behaviour without warning; or in some cases, with deliberate concealment of indicators and warnings.

A solution to the limitations of the existing model is the implementation of an alternative risk model that considers an individual's ability (capability) and desire (intent) to conduct threat activities. The consideration of capability and intent is considered a more rigorous and realistic assessment of risk that an individual poses both internal to a facility and when operating external to the IDN.

The proposed alternative risk model aligns with the ASIO [Australian Security Intelligence Organisation] Threat Methodology and that used within the Australian Intelligence Community (AIC) (pp5-6, emphasis added).

The emphasis on capacity and docility is turned not towards the induction in the regimen of the military, family or factory and what has occurred in the past, but, instead, to the behavioural repertoire of the neoclassical subject and whether or not detainees have the capacity and desire to be a threat in the future. While retaining various conventional understandings of risks (as in the use of statistics), significantly, it abandons the assumptions of a linear trajectory of 'threat activities' and stresses estimates of the ability and 'desire' of individuals to engage in such without warning. While risk management strategies within detention are preoccupied with specific risks (as in the possibility of losses as a result of property destruction, 'reputational risk' to the company, and so on) posed by the collision between the detention system's creation of 'pathway uncertainty' and the threat capacity and desire of the 'random variable', the analytic of risk combines these processes along with the techniques of contingency accounting and the similar contractual arrangements in such a way that it becomes possible not only to weigh estimates of possible losses with possible gains but also, importantly, to optimise the uncertainty that is generated both by the system and in its violent encounter with the movements of people across borders.

The largest operator in the IDN, Transfield, began as a civil and mining engineering company in the 1950s, and more recently transformed into an

40. The latter design, trademarked as 1473174 , was lodged on 07.02 .2012 , and the owner of the trademark is registered as Transfield Services (Australia). infrastructure, services and investment conglomerate. Its in-house magazine, Transverse, swings between the block-lettered aesthetics of its engineering history and the more recently trademarked logo of a "concentric circles, incomplete form curl' design.$^{40}$ The latter design is suggestive of a jet turbine, and it perhaps does not go without saying that the concept of transversality is a prominent one in the works of Deleuze and Guattari - a concept that points to the iteration of concepts across domains, without recourse to 
identity (transitive or predicated classes); or, as Guattari put it, 'a machine of production and expression of desire that demands to be applicable everywhere'. ${ }^{41}$ The processes outlined here have transformed the state as much as they have corporations because some of their recent history has involved the standardisation of what Wood calls the "technical infrastructure of global capitalism', including that of the codification of risk. ${ }^{42}$ Infrastructure construction has conventionally involved an allowance for contingencies in estimates because of the multiple contractors and contracts it assembles around huge amounts of money over a lengthy period of (precarious) time from tender to operation and shutdown. ${ }^{43}$ Infrastructure supply-chains have long been the laboratories of financial engineering, risk-shifting and organisational consortia - as with Public-Private Partnerships (PPPs), in the use of subcontracting or outsourcing arrangements, Private Finance Initiatives (PFIs), and Special Purpose Vehicles (SPVs). It is also a world marked by the inter-related rise of investment and retirement funds, and an accompanying blending of financial and actuarial instruments such as ILSs and derivative contracts.

Transfield's most recent contract for $\$ 1.2$ billion (AUD) includes an additional $\$ 900$ million for 'unspecified contingencies', thus, at $\$ 2.1$ billion (AUD), making it the largest single contract in the IDN. The current prevalence of such contracts can be traced to the emergence of 'contingency theory', generally situated in the early 1960s and beginning with Burns and Stalker's The Management of Innovation. ${ }^{44}$ Contrasted with the perceived epistemological limitations of scientific management and human relations paradigms (prevalent in the 1950s) in navigating the perceived volatilities of the 1960s, the canonical uptake of Burns and Stalker's ideas about contingency management and innovation hinged on a rudimentary typology of hierarchical and decentralised organisational forms, a related emphasis on the intransitive and unpredictable vagaries of the market and the mechanism of technological innovation (or adaptation) - echoing some of the ways in which Foucault, Deleuze and Guattari described a shift from societies of discipline to those of control. Burns and Stalker's work had been part of a more general shift toward contingency within the study of organisations, a move that went from depicting organisations as closed systems to characterising them as open to more or less predicted variables ranging from the size of the organisation to external factors. The aim of contingency theory in management studies was to guide the optimisation of organisational performance and decision-making in uncertain circumstances.

In accounting systems, contingencies are defined as those circumstances or conditions for which there is uncertainty in the present time as to possible gains or losses, an uncertainty that will be resolved when events occur or fail to occur in the future. They define a method of accounting for uncertainty, referring to that which is beyond the calculable register of risk but which nevertheless, and precisely for this reason, is a part of the analytics of risk
41. Félix Guattari, 'La Transversalité', in Psychanalyse et transversalité. Essais d'analyse institutionelle, $\mathrm{La}$ Découverte, Paris 2003, pp72-85.

42. Stepan Wood, 'The International Organization for Standardization', in Peter Utting, Darryl Reed and Ananya Mukherjee Reed (eds), Business Regulation and Non-State Actors: Whose Standards? Whose Development?, Routledge, New York 2012, p81; International Organization for Standardization, Risk Management - Principles and Guidelines: $B S$ ISO 31000:2009. Management $D u$ Risque, Principes et Lignes Directrices, International Organization for Standardization, Geneva 2009.

43. See Akintola Akintoye, Matthias Beck and Cliff Hardcastle (eds), Public-Private Partnerships: Managing Risks and Opportunities, Wiley, London 2003, p41. http://doi.org/d4svdb

44. The Management of Innovation, Tavistock, London 1996. 
45. Australian Accounting Standards Board, 'Compiled AASB Standard, AASB 137: Provisions, Contingent Liabilities and Contingent Assets', Commonwealth Government of Australia 2010.

46. 'Department of Immigration and Border Protection, Annual Report, 2012-13', Commonwealth Government of Australia 2013, p341.
47. To mention only one of these: Ayelet Shachar, 'The Shifting Border of Immigration Regulation', Michigan Journal of International Law, 30, management. They specify levels and types of disclosure or reporting as to their nature, timing and amount, or specify caveats and circumstances. The International Accounting Standard (IAS) 37 - issued by the IAS Committee (IASC) in 1998 - defines contingency as either 'a possible asset that will be confirmed by uncertain future events' or 'a possible obligation that will be confirmed by future events'. ${ }^{45}$ Contingency accounting involves the relative weighting of possible losses and gains, and it sets the conditions of possible liabilities and gains situated off the balance-sheet but within the notes of financial disclosure statements. The DIBP's Annual Report for 2012-13 is subtitled 'people our business'. It only consists of three sections: 'Performance', 'Management and Accountability', and 'Financial Statements'. In the latter, a financial note under the heading of 'Contingent Liabilities and Assets' is presented 'along with information on significant remote contingencies and contingencies that cannot be quantified' ${ }^{46}$ It further defines the contingency as an interaction between possible, unquantifiable, gains and losses, and notes the off-balance-sheet procedure:

assets and liabilities are recognised in the balance sheet when and only when it is probable that future economic benefits will flow to the department or a future sacrifice of economic benefits will be required and the amounts of the assets or liabilities can be reliably measured.

The role of contingency arrangements in the risk-shifting dynamics of outsourcing are also noted under revenues, and the report goes on to outline the significance of both fixed and variable financial contract arrangements as follows:

The funding model has fixed and variable components, with variable funding adjusted to reflect actual movements in workload in line with movements in the department's key workload drivers (i.e. visa finalisations, citizenship decisions and border movements) (p353).

An additional 'no-win no-loss' insulates contractors' revenues from the fluctuations (or, more precisely, falls) in the numbers of people detained. This stipulation immunises (to some extent) contractors from possible declines in revenue as a consequence of declining numbers of detainees or a change in policy. More broadly, the increasing prominence of contingency accounting methods illustrates the extent to which variable contracts and contingency accounting procedures not only make possible the collection of government, non-government and corporate entities, but do so in a context understood as inherently variable and through contractual arrangements that are turned toward the combined possibilities of presently unquantifiable losses and gains in the future.

There has been a good deal of critical analysis of the extraterritorial and 
indefinite arrangements of the IDN, but to my knowledge nothing on the ways 3 (2009), 809-39. in which this spatial ordering links to financial processes and strategies. ${ }^{47}$ Yet to explain the kind value generated by the system and the meaning of risk and uncertainty within it, it is important to include three additional islands in the archipelago: Bermuda, England and Cockatoo Island. The largest shareholder of Transfield (Allan Gray) is an investment management company registered in Bermuda, and Bermuda has been pivotal not only to corporate off-shoring strategies but also to the rapid development of hedging instruments such as insurance-linked securities, including catastrophe bonds. ${ }^{48}$ Australia is still - in legal, political and cultural terms - a possession of the English Crown, and London has been crucial to the growth of contingent financial contracts, as with contingent convertible bonds (CoCo bonds). ${ }^{49}$ The first point is this: central to each of these financial contracts are imagined estimates of future, indeed catastrophic, uncertainties bounded in the finite time of contracts; in stark contrast to the ways in which the IDN creates uncertainty in the present time among those it detains on an indefinite basis. Cockatoo Island, situated in the Sydney Harbour and site of Australia's largest arts festival - founded and, until very recently, sponsored by Transfield - may well seem anomalous to these processes, but it highlights the second point, which regards the integral significance of aesthetic and affective treatments of uncertainty to those processes, and in the experimental trajectory of financial engineering practices and their methods of risk analysis.

Contemporary risk analytics, particularly those related to hedging, are concerned not with discrete values (risks or losses), nor only with the connection between diverse values, but with gleaning a measure of the risk of risk (as in the derivative) through the correlation of uncorrelated - oftentimes imagined, therefore aesthetic - volatilities. By early 2014, Transfield's growing involvement in the detention industry had become a subject of controversy, particularly in the context of its prominent sponsorship of the Biennale of Sydney. Luca Belgiorno-Nettis, Chair of the Biennale (and co-owner of Transfield Holdings, the parent company of Transfield Services), was faced with mounting calls for a boycott of the Biennale; protests by detainees on Manus Island that were brought to an end through the injury of hundreds and the death of Reza Barati; $;^{50}$ and the public withdrawal of artists and staff from the event on the grounds that they did not wish to be associated with delivering any value to a company that profited from mandatory detention. He resigned almost a week before the event, announcing: 'I hope that blue sky may now open over this 19th @biennalesydney'. ${ }^{51}$ Transfield is no longer a sponsor of the Biennale of Sydney, the Belgiorno-Nettis family have since sold their shares, and they have very recently withdrawn Transfield Services' license to make use of their brand, including the logo and name. ${ }^{52}$ 'Blue sky', of course, is a term associated with speculative investments. While much of the debate around Transfield's presence at an arts festival turned on the claim of an inherent discrepancy between the creative arts and the detention industry,

48. Hélyette Geman, Insurance and Weather Derivatives: From Exotic Options to Exotic Underlyings, Risk, London 1999.

49. Alex C. Castles, 'The Reception and Status of English Law In Australia', Adelaide Law Review, 2, 1 (1963), 1-32.

50. These are the 'statistics' referred to in the epigram above, conveyed to me in private communications from a staff member who was present on Manus Island at the time. For more on the death of the Kurdish asylum-seeker Reza Barati and the injuries sustained by hundreds of other detainees, see Ben Eltham, 'The Truth About Reza Barati Must Be Told', New Matilda, 1.4.14: https://newmatilda. com/2014/04/01/ truth-about-rezabarati-must-be-told.

51. Alana Lentin and Javed da Costa, 'Sydney Biennale Boycott Victory Shows That Divestment Works', Guardian, 11.3.14: www. theguardian.com/ commentisfree/2014/ mar/11/sydneybiennale-boycottvictory-shows-thatdivestment-works.

52. This was announced just as I was placing the final touches on this article, though it will likely take some months to be take effect. 
53. http://www. biennaleofsydney. com.au/exhibition/ exhibition-overview/.

54. Mats Lindgren and Hans Bandhold, Scenario Planning: The Link between Future and Strategy, Palgrave Macmillan, New York 2003.

55. Acting in an Uncertain World: An Essay on Technical Democracy, MIT Press, London 2011, p21.

\section{Garry D.} Peterson, Graeme S. Cumming, and Stephen R. Carpenter, 'Scenario Planning: A Tool for Conservation in an Uncertain World', COBI Conservation Biology 17, 2 (2003), 358-66. there is a point to the close alignment of financial and aesthetic registers of the speculative. Luca Belgiorno-Nettis's remark about 'blue sky' underlines the importance of speculation to both the investment firm of Transfield Holdings and the artistic practices of the Biennale.

Less obviously perhaps, it points to the ways in which the Biennale had already been shaped by the aesthetic dimensions of risk analytics. Curated by Juliana Engberg, the 21st Biennale of Sydney was titled 'You Imagine What You Desire'. It was billed as a celebration of 'the artistic imagination as a spirited describing and exploration of the world through metaphor and poesis': 'It makes enquiries into contemporary aesthetic experience, and relates this to historical precedents and future opportunities to imagine possible worlds. ${ }^{53}$ The concept of possible worlds has long been a formulation of modal logic. It is also one of the key practices of risk management, as in the case of scenario planning. Recall that probabilities are weights ascribed to possible worlds drawing on inferences from past frequencies. The limits of these, as noted above, include the initial assigned pick of the variables, the formulation of constants, priors, and nominalism (or predicates) derived from past frequencies or norms. Seeking to move beyond these limits, there has been an increasing emphasis on 'the art' of risk analysis. ${ }^{54}$ In their discussion of Knightian uncertainty and calculable risk, Callon et al propose the use of 'hybrid forums' through which to move beyond the limits to probabilistic knowledge and toward an experimental and speculative grasp of uncertainty:

science often proves to be incapable of establishing the list of possible worlds and of describing each of them exactly ... We know that we do not know, but that is almost all that we know: there is no better definition of uncertainty ... Hybrid forums help to bring some elements of an answer to these pressing questions. ${ }^{55}$

Such calls for the 'hybridisation' of risk analytics - the blending of aesthetic, financial and scientific practices, or a variety of methods for introjecting the incalculable into the calculable through forums involving practitioners across these fields and techniques - has been a mainstay of discussions of risk for the previous thirty years. What is remarkable about the appearance of such a programme within the Biennale is less that the conjuncture between 'historical precedents' and 'future opportunities' is a fairly precise rendition of the path-dependency of possible world scenarios; ${ }^{56}$ or even that it presents the Biennale as an instance of a 'hybrid forum'; it is, rather, that the aestheticallyimmersive, edgy-but-safe enjoyment and marketing of uncertainty ('You Imagine What You Desire') contrasts with the active creation of 'pathway uncertainty' presented in the Serco report, whose consequences go on to be dealt with by a focus on the non-linear threat assessments of detainees' 'desire' for non-compliance, and so on. Risk-shifting involves convoluted processes (coils), but the circuits of capital nevertheless have a clear goal. 
Both Bermuda and Nauru have been characterised as Offshore Financial Centres (OFCs) or, less politely, as a tax havens. As Zorone's study of OFCs found, the 'use of offshore vehicles by corporations and high-networth individuals generally obeys one fundamental principle: 'to capture higher return on investments, in exchange for services fees paid to the host jurisdictions' ${ }^{57}$ Parking and isolating what are often high-risk assets from disclosure, regulations, possible expropriation, (inheritance) taxes or liabilities means that accounting systems - even as this could be described as giving effect to unaccountability beyond the boundaries of a company, wealthy individual and/or family - involves spatial instruments which give rise to the concept of off-shoring even as they involve a range of techniques for shoring-up or capturing a 'higher return of investments'. 'Off-shored' is the accounting equivalent of 'off balance sheet', but it is not outside the balance sheet known to shareholders nor outside state power and laws. As with the detention centres on Nauru and Manus Island, offshoring allows for the calibration of the scope of disclosure and regulation - much as habeas corpus and asylum seeker and refugee law, while still law, are in practice voided by extraterritorial off-shoring and excision. ${ }^{58}$

In May 2014, Transfield raised just over $\$ 346 \mathrm{~m}$ (AUD) from an issue of CoCo bonds (contingent convertible notes) on the unsecured US bond market, with a remarkably high coupon rate of 8.375 per cent and a maturity date of May 2020. The contingent convertible is often referred to as a hybrid form of financing since it mixes debt and equity, granting the bondholder the right to convert or exchange the face value of the bond for regular shares of the issuer at some fixed ratio during a particular period. In other words, while the structure of particular convertibles can be more or less complicated, they derive their value from speculations on the divergent ratio within a set period of time, giving companies a means of raising finances other than through the debt market. CoCo bonds are associated with high-debt (low credit rated) companies considered to have high growth potential, such as Transfield, whose debt-equity ratio was extremely high even before its increasing involvement in detention management, but whose expansion in outsourcing - including that of detention contracts - is at the same time seen as highly likely. As with CoCo bonds, ILSs can be predicated on the trigger of maturity dates, but it is the drawing together of divergent patterns of temporally-understood volatility that accords them with a particular value; and it is illustrative of the way in which the archipelagic combination of divergent frequency distributions is crucial to financial markets and the hedge funds that dominate the share registers of companies involved in migration detention. Insurance-backed securities - such as catastrophe bonds (cat bonds) - derive their value from speculations on the probability of low-frequency, high-loss events such as earthquakes or hurricanes uncorrelated to the fluctuations of the market. This non-market indices is what makes them attractive to investors. Cat bonds act as instruments of hedging or portfolio diversification by enabling the calculation
57. Concept of Offshore Financial Centers: In Search of an Operational Definition, International Monetary Fund, Washington, DC 2007, pp7-8.

58. See Prem Kumar Rajaram and Carl Grundy-Warr (eds), Borderscapes: Hidden Geographies and Politics at Territory's Edge, University of Minnesota Press, Minneapolis 2007. 
of relative risk, the reckoning the ratio of probabilities of financial markets against the probabilities of 'natural perils' such as earthquakes and hurricanes (or 'acts of God'), terrorism, climate change, or even apocalyptic events such as human extinction. In return for above-market yields, investors assume the risk of a catastrophic event during the term of the bonds. The principal is held by a SPV as highly-rated collateral. It is paid out to the insurer or re-insurer to cover its losses in the event of a specified catastrophe's occurrence.

The point of this is not simply a descriptive: that some of Transfield's largest shareholders are registered in Bermuda, make use of such financial instruments as a matter of course, or indeed that the joint public-private development of infrastructure funding has increasingly been premised on the use of 'hybrid' financial instruments such as ILS and CoCo bonds in which, often enough, the function of the vast pool of retirement funds is to collateralise securities trades such as the issuing of CoCo bonds in unsecured markets. All of this poses interesting questions, not least of which is the relationship between border control, national security, social security, the companies that oftentimes traverse each of these fields, and the disastrous or apocalyptic imaginings that these depend upon for analysis and value. The more specific point is that in the analytics of risk it is the correlation of otherwise uncorrelated frequencies of event distribution and speculations on the future in bounded sets of comparable but diverse times that generates value - this is the archipelago of risk, and it makes sense as a (non-equilibrium) response to Knight's theory of uncertainty as I have outlined it here. It is an assemblage in that the compilation of statistics on high-frequency, highrisk events (of death, suicides in detention) occurs alongside speculations on low-frequency, high-risk event distributions of catastrophic events, along with estimates of the likelihood of debt default and high contract yield - in a system that depends on the plausible depiction of imagined threats.

\section{BY WAY OF A CONCLUSION}

It is the assemblage that matters in the analytics of risk, and that assemblage is not without determination, techniques, scope and conditions. In this sense, the archipelago of risk is amenable to theorisation without lapsing into a naturalist theory of risks, precisely because uncertainty operates within its analytics as an immanent (indeed aesthetic and affective) rather than transcendental mechanism of selection. The border persists as the condition of above-average profits (or losses). Furthermore, the epistemic (perhaps geographic) partition between analyses of risk and those of the (prison or) border industrial-complex has resulted in a neglect of the ways in which this field exemplifies an increasing indistinction between states and corporations as well as socio-technical systems through which race is materialised, as both ideational construct and generative taxonomy of organisational processes. The same could be said of prevalent understandings of class, which at times 
seems unrelated to the concept of classification and its changing sociotechnical systems. That said, the above essay, besides offering a theory of the dynamics of the risk archipelago, extends Deleuze's plea in the 'Postscript' to eschew both optimism and pessimism and look instead at how systems function - and on occasion no longer do so, because such systems are already responses to variables they did not and cannot account for or anticipate. The analysis offered here is critical of Foucault's, Deleuze and Guattari's theories in some respects - the emphasis falls not on fixed canonical positions but on the 'socio-technological study of the mechanisms of control'. ${ }^{59}$ The 'new forms of resistance' that deploy around the IDN and related questions are not, I think, those of the re-enchantment of 'life', nor those of human rights and ethics - not least because these are premised on transcendental claims that, in practice, are firmly within the immanent frame of risk analytics, as has been apparent in the use of business ethics or the presence of faith-based agencies as contractors within the IDN. Rather, the new forms of resistance are those which focus on the principal mechanisms of risk allocation (contracts), on the significance of circulation and speculative estimates to its processes (such as boycotts, disinvestment and similar), and on infrastructure to its organisational form.

Angela Mitropoulos has written extensively on borders and finance and is the author of Contract E Contagion: From Biopolitics to Oikonomia (2012). Her most recent published work is on social investment financing, and her current project is called 'Infrastructures of Uncommon Forms'.
59. 'Postscript on the Societies of Control', p7. By way of disclosure and as per experimental science, I advised some of the artists and staff who withdrew from the Biennale of Sydney and those who called for a boycott and also spoke publicly in favour of both actions. 